\title{
Cost of HAART in Italy: multicentric evaluation and determinants from a large HIV outpatient cohort
}

This article was published in the following Dove Press journal:

ClinicoEconomics and Outcomes Research

22 December 2014

Number of times this article has been viewed

\author{
Monica Tontodonati ${ }^{1,2}$ \\ Giovanni Cenderello 3 \\ Benedetto Maurizio Celesia ${ }^{4}$ \\ Michele Trezzi ${ }^{5}$ \\ Tamara Ursini \\ Andrea Costantini ${ }^{6}$ \\ Domenico Marra ${ }^{7}$ \\ Ennio Polilli ${ }^{8}$ \\ Corrado Catalani ${ }^{5}$ \\ Luca Butini ${ }^{6}$ \\ Federica Sozio ${ }^{8}$ \\ Elena Mazzotta9 \\ Antonina Sciacca ${ }^{8}$ \\ Giuliano Rizzardini ${ }^{10}$ \\ Lamberto Manzoli"I \\ Alessandro Cozzi-Lepri ${ }^{12}$ \\ Giustino Parruti ${ }^{8}$ \\ 'Infectious Disease Unit, Pescara General \\ Hospital, Pescara, ${ }^{2}$ Clinic of Infectious \\ Diseases, G D'Annunzio University \\ of Chieti-Pescara, Chieti, ${ }^{3}$ Division of \\ Infectious Disease, Galliera General \\ Hospital, Genoa, ${ }^{4}$ Infectious Diseases Unit, \\ ARNAS Garibaldi, Catania, ${ }^{5}$ Infectious \\ Diseases Unit, Pistoia General Hospital, \\ Pistoia, ${ }^{6} \mathrm{Clinical}$ Immunology Unit, Ancona \\ Hospital, Ancona, ${ }^{7}$ Division of Oncology, \\ Galliera General Hospital, Genoa, \\ ${ }^{8}$ Infectious Diseases Unit, Pescara General \\ Hospital, Pescara, 'Internal Medicine \\ Department, G D'Annunzio University of \\ Chieti-Pescara, Chieti, ${ }^{10}$ First Infectious \\ Diseases Department, Luigi Sacco Hospital, \\ Milan, "Section of Hygiene, Epidemiology, \\ Pharmacology and Legal Medicine, G \\ D'Annunzio University of Chieti-Pescara, \\ Chieti, Italy; ${ }^{12}$ Research Department of \\ Infection and Population Health, University \\ College London, London, UK
}

Correspondence: Monica Tontodonati Infectious Disease Unit, Pescara General Hospital, 65 I 24 Pescara, Italy. Email monicatontodonati@gmail.com
Background: As HIV infection turned into a chronic treatable disease, now ranking as one of the most costly in medicine, long-term sustainability of highly active antiretroviral treatment (HAART) expenses became a major issue, especially in countries with universal access to care. Identification of determinants of higher HAART costs may therefore help in controlling costs of care, while keeping high levels of retention in care and viral suppression.

Methods: With this aim, we enrolled a large multicentric sample of consecutive unselected human immunodeficiency virus (HIV) patients followed at five sites of care in Italy, and evaluated annual individual HAART costs in relation to a number of sociodemographic, clinical, and laboratory variables.

Results: We enrolled 2,044 patients, including 1,902 on HAART. Mean HAART costs were $€ 9,377 \pm € 3,501$ (range 782-29,852) per year, with remarkable site-based differences, possibly related to the different composition of local assisted populations. Percentages of patients on viral suppression were homogeneously high across all study sites. The factors identified by cross-validation were line of HAART, diagnosis of acquired immune deficiency syndrome, current CD4 T-cell count, and detectable HIV viremia $>50$ copies $/ \mathrm{mL}$. In the final multivariable model, HAART costs were independently directly associated with more advanced HAART line $(P<0.001)$ and inversely correlated with current CD4 T-cell count $(P=0.024)$. Site of care held independent prediction of higher costs, with marked control of expenses at sites $2(P=0.001)$ and $5(P<0.001)$.

Conclusion: Higher costs of HAART were strongly associated with previous treatment failures, detectable HIV viremia, and lower CD4 T-cell count at the time of evaluation, with no correlation at all with sex, age, hepatitis $\mathrm{C}$ virus coinfection, and nadir CD4 T-cell counts. Newer drugs, which are typically those associated with high prices, at the time of the analysis were still prevalently prescribed to rescue and maintain viral suppression in patients with more complex treatment history. Further analyses of the contribution of the single drug/regimen to the estimated cost are warranted.

Keywords: highly active antiretroviral treatment, human immunodeficiency virus, costs, treatment failures, viremia, current CD4 count

\section{Introduction}

With the advent of combined highly active antiretroviral therapy (HAART), human immunodeficiency virus (HIV) turned into a chronic treatable disease, compatible with near normal lifespan expectancy. ${ }^{1-3}$ As a consequence of increased survival of both early and advanced HIV infections, expenditure for HIV care is now ranking as one of the most costly chronic diseases. ${ }^{1,4}$ Indeed, even though costs for HIV hospital admissions have somewhat decreased, ${ }^{5,6}$ especially in patients with early diagnosis, 
total costs for HIV care are getting higher and higher in line with the following trends: increasing costs of newer antiretrovirals, larger numbers of patients on chronic therapy, guidelines suggesting early prescription of HAART, and early access to treatment as prevention..$^{5,7-10}$

The majority of industrialized countries strive to guarantee long-term sustainability for lifelong antiretroviral treatment of HIV patients. Universal access to care seems to be indeed helpful for patients' retention in care in some European countries like Italy and Denmark, where physicians may prescribe antiretrovirals in the absence of immediate control of expenses and current results regarding retention in care and HAART efficacy are suggestive of adequacy. ${ }^{11-14}$

As the costs of HAART regimens are relatively easy to determine and analyze, in the present study we set up a research protocol to retrospectively assess the issue of which factors are associated with the use of more costly HAART regimens in clinical practice. We wondered whether costs might be presently associated with sociodemographic and clinical features of our patients, or rather with other conditioning factors.

\section{Materials and methods}

A retrospective unselected sample of consecutive HIV outpatients aged $>18$ years and followed at five sites of care well spread throughout Italy was collected for a cross-sectional evaluation of cost determinants in 2012. We considered sociodemographic characteristics (age, sex), risk factors for HIV infection (heterosexual, homosexual, intravenous drug use, blood transfusion), current HIV viral load (copies/mL, Roche Amplicor ${ }^{\circledR}$ ), current (at the time of cost evaluation) and nadir CD4 T-cell counts (cells $/ \mathrm{mm}^{3}$ ), time from HIV diagnosis, acquired immune deficiency syndrome (AIDS)-defining events (ever reported during clinical history), current HAART line, and hepatitis $\mathrm{C}$ virus (HCV) coinfection, as already defined elsewhere. ${ }^{15}$ Years from HIV diagnosis were calculated as the difference between 2012 and the year when HIV infection was first diagnosed. Line of HAART was defined on the basis of the number of treatment changes due to virological failure; simplification or switch for side effects were not considered as a change of HAART line. Annual costs of individual HAART regimens were calculated using pharmacy data retrieved at each distribution site as of December 2012.

\section{Statistical analysis}

The outcome was the cost of the regimen currently used by the patients. Costs were modeled in the original raw scale as the distribution was approximately normal and the $\log$ transformation only marginally reduced the skewness. Univariable analyses for determinants of higher HAART costs were set up for all the investigated variables. The basic set of covariates were: line of HAART, age, AIDS event, current CD4 T-cell count, time since HIV diagnosis, coinfection with HCV, nadir CD4 T-cell count, risk for HIV infection, sex, and detectable HIV RNA >20 copies/mL. Initially, the potential independent predictors of HAART costs were evaluated using a multivariable regression model, including all covariates that were significantly associated with costs in the univariable analyses. Statistical significance was defined as a two-sided $P$-value $<0.05$ for all analyses, and multiple regression models were fit using Stata version 10.1 (Stata Corporation, College Station, TX, USA). In addition to this approach, three different criteria for the selection of covariates in the model were used, similar to what was done by Cozzi-Lepri et al: ${ }^{16}$ best subset least squared estimations, least absolute shrinkage and selection operator, ${ }^{17}$ and a mixed approach using both least angle regression and least absolute shrinkage and selection operator. ${ }^{18}$ In all these methods, model sequencing is determined by the original algorithm, while the coefficients of the parameters at each step are determined using ordinary least squares. Both least absolute shrinkage and selection operator and least angle regression are shrinkage methods for linear regression that minimize the sum of squared errors though with a bound on the sum of the absolute values of the coefficients given by a parameter $\mathrm{K}$. This parameter $\mathrm{K}$ was chosen to minimize the average squared error based on a 10-fold cross-validation. Briefly, to perform a 10-fold cross-validation means to randomly divide the dataset into ten portions of the same size. The method then fits the model for a range of values of $K$ to $9 / 10$ th of the data and computes the prediction error on the remaining $1 / 10$ th. This is done, in turn, for each of the $1 / 10$ portions, and eventually the mean of these ten obtained estimates of the prediction error is calculated. Using this approach, we obtained an estimated prediction of the 10-fold cross-validation error (CV PRESS) curve as a function of the model evolution steps. This was used to establish at which step to stop the inclusion of the covariates. Specifically, the "one-standard-error" rule was used to select the final model: the model with the smaller number of included covariates providing a CV PRESS within one standard error of its minimum value. Cross-validation was applied to our database (by randomly splitting 50\% as training, $25 \%$ as validation, and $25 \%$ as test set) to select $\mathrm{K}$ for all estimation procedures. Of note, the training set is used to determine the coefficients but not to decide when to stop. 
The results of the cross-validation in terms of selection of the most important predictors were similar when using the costs in the raw or the log scale. All these additional analyses were performed using the procedure GLMSELECT in SAS version 9.3 (SAS Institute, Cary, NC, USA).

\section{Results}

We included 2,044 patients, $69.0 \%$ of whom were male. The mean patient age was $46.9 \pm 10.0$ years, and $33.4 \%$ of patients were coinfected with HCV. The risk for HIV infection was heterosexual contact ( 881 patients, 43.7\%), homosexual contact (519 patients, $25.7 \%$ ), intravenous drug use (591 patients, $29.3 \%$ ), and blood transfusion (25 patients, 1.2\%). Mean time since HIV diagnosis was $13.6 \pm 7.9$ years. Mean nadir CD4 T-cell counts were $230.0 \pm 169.3$ cells $/ \mathrm{mm}^{3}$, mean current CD4 T-cell counts were $579.0 \pm 299.0$ cells $/ \mathrm{mm}^{3}$. An AIDS diagnosis was recorded for $30.8 \%$ of patients. Significant differences in demographic and clinical features were observed between patients cared for at different sites, as shown in Table 1 .

There were 1,902 (93.0\%) evaluable patients on HAART. Among them, viremic ( $\geq 20$ copies $/ \mathrm{mL}$ ) patients were $31.2 \%$ (635 patients); only $19.0 \%$ (387 patients), however, had HIV RNA values $>50$ copies/mL. Median HAART line was 3.47 \pm 2.08 . Mean individual HAART costs were $€ 9,377 \pm € 3,501$ (range 782-29,852) per year. Costs were significantly different at the five sites of care, as indicated in Table 1.

Univariable analyses for higher HAART costs were set up for all the investigated variables. All of them were associated with higher HAART costs with the exception of sex, as shown in Table 2.

When we used the best subset selector least squared estimates of the coefficients and 10-fold cross-variation to identify our best multivariable predictive model, starting from the full set of measured variables, the following factors were selected: line of HAART (parameter estimate $=+€ 557$ per additional regimen), AIDS diagnosis (estimate $=+€ 351$ compared with asymptomatic), current CD4 T-cell count (estimate $=-€ 629$ for those having $>200$ and $<500$ cells $/ \mathrm{mm}^{3}$ current CD4 count comparing with those having $\leq 200$ cells $/ \mathrm{mm}^{3}$, and $-€ 1,135$ for those having $>500$ cells $/ \mathrm{mm}^{3}$ current CD4 count) and HIV viral load $>50$ copies $/ \mathrm{mL}$ (estimate $=+€ 405$ compared with viral load $\leq 50$ copies $/ \mathrm{mL}$ ). Figure 1 shows the relative importance of these factors at each step of the selection process, and provides information as to when effects entered the model (the estimates above are derived directly from the standardized coefficients at final step number 4; a negative estimate means a negative impact on costs). Thus, for example, the line of HAART is the first factor to be entered in the model with an estimated coefficient close to 0.4 (step 1). In the following three

Table I Demographic and viro-immunological characteristics of the sample overall and by site

\begin{tabular}{|c|c|c|c|c|c|c|c|}
\hline Site (patients) & $\begin{array}{l}\text { Overall } \\
(n=2,044)\end{array}$ & $\begin{array}{l}\text { Site I } \\
(n=24 I)\end{array}$ & $\begin{array}{l}\text { Site } 2 \\
(n=464)\end{array}$ & $\begin{array}{l}\text { Site } 3 \\
(n=690)\end{array}$ & $\begin{array}{l}\text { Site } 4 \\
(n=285)\end{array}$ & $\begin{array}{l}\text { Site } 5 \\
(n=364)\end{array}$ & $P$-value* \\
\hline Male sex, n (\%) & $\mathrm{I}, 410(70.0)$ & I 78 (73.9) & $300(64.6)$ & $46 \mid(66.8)$ & $221(77.5)$ & II 4 (68.7) & 2vsI; 3vsI; 4vs2; 4vs3; 5vs4 \\
\hline Mean (SD) age, years & $46.9(10.1)$ & $45.5(9.1)$ & $45.2(8.9)$ & $49.0(9.2)$ & $46.6(11.2)$ & 47.7 (II.4) & 3vs1; 3vs2; 4vs3; 5vs3 \\
\hline IVDU, n (\%) & $591(29.3)$ & $60(24.9)$ & $105(22.6)$ & $289(42.6)$ & $51(17.9)$ & $86(24.8)$ & $3 v s 1 ; 3 v s 2 ; 4 v s 3 ; 5 v s 3 ; 5 v s 4$ \\
\hline AIDS, n (\%) & $615(30.8)$ & $96(39.8)$ & I5I (32.5) & $220(31.9)$ & 51 (I7.9) & $97(30.4)$ & 3vsI; 4vsI; 4vs2; 4vs3; 5vsI \\
\hline $\begin{array}{l}\text { CD4 T-cell nadir, } \\
\text { mean (SD) }\end{array}$ & $232(171)$ & $237(186)$ & $255(187)$ & $187(1 \mid 4)$ & $325(230)$ & $211(135)$ & $\begin{array}{l}\text { 2vs1; 3vs2; 4vs1; 4vs2; } \\
4 v s 3 ; 5 v s 2 ; 5 v s 4\end{array}$ \\
\hline $\begin{array}{l}\text { Current CD4 T-cell } \\
\text { count, mean (SD) }\end{array}$ & 579 (299) & $5 I I(280)$ & $592(305)$ & $552(287)$ & $681(340)$ & $578(270)$ & $4 \mathrm{vs} 1 ; 4 \mathrm{vs} 2 ; 4 \mathrm{vs} 3 ; 5 \mathrm{vs} 4$ \\
\hline $\begin{array}{l}\text { Naïve to HAART, } \\
\text { n (\%) }\end{array}$ & $142(7.0)$ & $20(8.3)$ & $60(12.9)$ & $22(3.2)$ & $40(14.0)$ & $0(0)$ & $\begin{array}{l}3 \mathrm{vsl} ; 3 \mathrm{vs} 2 ; 4 \mathrm{vsl} ; 4 \mathrm{vs} 3 \\
5 \mathrm{vs} 1 ; 5 \mathrm{vs} 2 ; 5 \mathrm{vs} 3\end{array}$ \\
\hline HCV coinfection, $n(\%)$ & $682(33.4)$ & $68(28.2)$ & $129(27.8)$ & $317(45.9)$ & $77(27.3)$ & $91(25.0)$ & $3 v s 1 ; 3 v s 2 ; 4 v s 3 ; 5 v s 3$ \\
\hline $\begin{array}{l}\text { Mean (SD) time from } \\
\text { HIV infection, years }\end{array}$ & I3.6 (7.9) & I3.2 (7.4) & $13.9(8.4)$ & I5.5 (7.7) & $8.2(5.2)$ & $12.3(7.6)$ & $\begin{array}{l}3 v s 1 ; 3 v s 2 ; 4 v s 1 ; 4 v s 2 ; \\
4 v s 3 ; 5 v s 2 ; 5 v s 3 ; 5 v s 4\end{array}$ \\
\hline $\begin{array}{l}\text { Detectable viremia } \\
>20 \mathrm{cp} / \mathrm{mL}, \mathrm{n}(\%)\end{array}$ & $635(31.2)$ & $68(28.3)$ & $112(24.2)$ & $306(44.4)$ & $85(30.1)$ & $64(17.6)$ & $\begin{array}{l}3 \mathrm{vs} 1 ; 3 \mathrm{vs} 2 ; 4 \mathrm{vs} 3 ; 5 \mathrm{vs} 1 ; \\
5 \mathrm{vs} 3 ; 5 \mathrm{vs} 4\end{array}$ \\
\hline $\begin{array}{l}\text { Detectable viremia } \\
>50 \mathrm{cp} / \mathrm{mL}, \mathrm{n}(\%)\end{array}$ & $387(19.0)$ & $47(19.6)$ & $103(22.3)$ & II4 (I6.6) & $59(21.0)$ & $64(17.6)$ & NS \\
\hline $\begin{array}{l}\text { Mean (SD) HAART } \\
\text { costs, } €\end{array}$ & $9,377(3,501)$ & $9,168(3,252)$ & $8,881(3,600)$ & $10,042(3,322)$ & $9,515(2,876)$ & $8,728(4,028)$ & $3 v s 1 ; 3 v s 2 ; 5 v s 3 ; 5 v s 4$ \\
\hline
\end{tabular}

Notes: CD4 T-cell counts are expressed as cell/mm $\mathrm{mm}^{3}$. HAART costs are calculated as annual costs of HAART per single patient. Site I, Pescara; site 2, Ancona; site 3, Genoa; site 4, Pistoia; site 5, Catania. *One-way analysis of variance with Sidak correction for continuous variables, chi-squared test for categorical variables. Head-to-head comparisons among groups were made and are reported as follows: ie, 3 vs 2 means that the comparison between group 3 and group 2 was significant $(P<0.05)$.

Abbreviations: AIDS, acquired immune deficiency syndrome; cp, copies; HAART, highly active antiretroviral therapy; HCV, hepatitis C virus; HIV, human immunodeficiency virus; IVDU, intravenous drug use; NS, any difference across groups was significant; SD, standard deviation. 
Table 2 Individual annual HAART costs according to selected variables

\begin{tabular}{|c|c|c|}
\hline & Mean (SD) cost, $€$ & $P$-value* \\
\hline Sex & & 0.6 \\
\hline Male & $9,400(3,585)$ & \\
\hline Female & $9,324(3,309)$ & \\
\hline HAART line & & $<0.001$ \\
\hline First & $8,016(2,3 \mid I)$ & \\
\hline Second & $8,185(2,000)$ & \\
\hline Third & $8,915(2,656)$ & \\
\hline Fourth & $9,545(2,801)$ & \\
\hline Fifth & $10,065(3,530)$ & \\
\hline Sixth & $10,733(4,3 \mid I)$ & \\
\hline Seventh & $\mathrm{II}, 4 \mid 5(5,49 \mid)$ & \\
\hline Eighth & I3,077 (5,909) & \\
\hline IVDU & & 0.0001 \\
\hline No & $9,189(3,434)$ & \\
\hline Yes & $9,860(3,647)$ & \\
\hline AIDS & & $<0.001$ \\
\hline No & $9,090(3,102)$ & \\
\hline Yes & $10,015(4,043)$ & \\
\hline HCV coinfection & & 0.0007 \\
\hline Negative & $9,187(3,476)$ & \\
\hline Positive & $9,750(3,525)$ & \\
\hline Detectable viremia $\geq 20 \mathrm{cp} / \mathrm{mL}$ & & $<0.00$ I \\
\hline No & $9,098(3,285)$ & \\
\hline Yes & $|0,07|(3,909)$ & \\
\hline Detectable viremia $\geq 50 \mathrm{cp} / \mathrm{mL}$ & & 0.0012 \\
\hline No & $9,265(3,300)$ & \\
\hline Yes & $9,959(4,363)$ & \\
\hline Mean time from HIV infection & & $<0.001$ \\
\hline$<10$ years & $8,795(2,54 I)$ & \\
\hline $10-20$ years & $9,572(3,778)$ & \\
\hline$>20$ years & $10,125(4,090)$ & \\
\hline CD4 T-cell nadir, cells $/ \mathrm{mm}^{3}$ & & $<0.001$ \\
\hline$\leq 200$ & $9,855(3,870)$ & \\
\hline $201-499$ & $8,944(3,040)$ & \\
\hline$\geq 500$ & $8,644(3,115)$ & \\
\hline Current CD4 T-cell count, cells $/ \mathrm{mm}^{3}$ & & $<0.001$ \\
\hline$\leq 200$ & $10,682(4,357)$ & \\
\hline $201-499$ & $9,656(3,798)$ & \\
\hline$\geq 500$ & $9,026(3,057)$ & \\
\hline Mean age, years & & 0.0003 \\
\hline$<36$ & $8,410(2,782)$ & \\
\hline $36-50$ & $9,388(3,547)$ & \\
\hline$>50$ & $9,668(3,582)$ & \\
\hline Clinical site & & 0.0001 \\
\hline Site I & $9,168(3,252)$ & \\
\hline Site 2 & $8,881(3,600)$ & \\
\hline Site 3 & $10,043(3,322)$ & \\
\hline Site 4 & $9,515(2,876)$ & \\
\hline Site 5 & $8,728(4,028)$ & \\
\hline
\end{tabular}

Notes: *Kruskal-Wallis test. HAART line was treated as a continuous variable. Abbreviations: AIDS, acquired immune deficiency syndrome; cp, copies; HAART, highly active antiretroviral therapy; HCV, hepatitis $C$ virus; HIV, human immunodeficiency virus; IVDU, intravenous drug use; SD, standard deviation.

steps, a diagnosis of AIDS, having a viral load $\leq 50$ copies/ $\mathrm{mL}$ and current CD4 count were added into the model, respectively. For further analyses, see Supplementary material and Figure S1.
Finally, we also fitted the full model including all factors measured and collected in the database, which were found to be significant at univariate analyses. This was done to verify whether the factors identified through cross-validation had an independent effect on costs after controlling for all other variables. The results of this full regression model are shown in Table 3. HAART costs were independently directly correlated with the number of HAART lines used (the cost was $€ 592$ higher per each additional line of therapy used, 95\% confidence interval 518-665, $P<0.001$ ); in contrast, they were inversely correlated with current CD4 T-cell count (€674 less expensive for patients having a current CD4 count $>200$ and $<500$ cells $/ \mathrm{mm}^{3}$ versus those having a current CD4 count $\leq 200$ cells $/ \mathrm{mm}^{3}, 95 \%$ confidence interval $-1,281,-68$, $P=0.029$; and $€ 1,136$ less expensive for those having a current CD4 count of $>500$ cells $/ \mathrm{mm}^{3}, 95 \%$ confidence interval $-1749,-523, P<0.001)$ and $\mathrm{HCV}$ coinfection (€527 less expensive than $\mathrm{HCV}$-negative patients). Independent prediction of higher costs was confirmed for the site of care in the full regression model, with marked control of expenses at site 2 (€743 less expensive, 95\% confidence interval $-1139,-347$, $P<0.001)$ and site $5(€ 1,224$ less expensive, $95 \%$ confidence interval $-1,675,-774, P<0.001)$.

\section{Discussion}

We evaluated the raw costs of HAART, calculated as at December 2012, in a multicenter Italian sample of HIV outpatients, to derive a comparative estimate at different sites of care and identify potential determinants of more costly HAART regimens. In our search for such determinants, we investigated the possible correlation between HAART costs and many clinical and demographic factors, including the burden of toxicities and comorbidities affecting the single patient as accounted for by a multifactorial risk score. ${ }^{19}$ Preliminary analyses, performed for patients followed at site 1 only, unexpectedly revealed that HAART costs were not correlated at all with comorbidities and HAART toxicities, as evaluated by such a score; in that analysis, costs were indeed significantly associated with other measurable factors, such as more advanced HAART lines, lower nadir and current CD4 T-cell counts, AIDS events, HCV coinfection, age, years from HIV diagnosis, and detectable HIV viremia. We therefore evaluated all these factors in this final multicenter sample, in order to better estimate the independent weight of each determinant of HAART costs.

The mean annual cost of HAART was $€ 9,377 \pm € 3,501$ per single patient, in line with the only comparable Italian data, reported by Rizzardini et al, who quantified such costs 


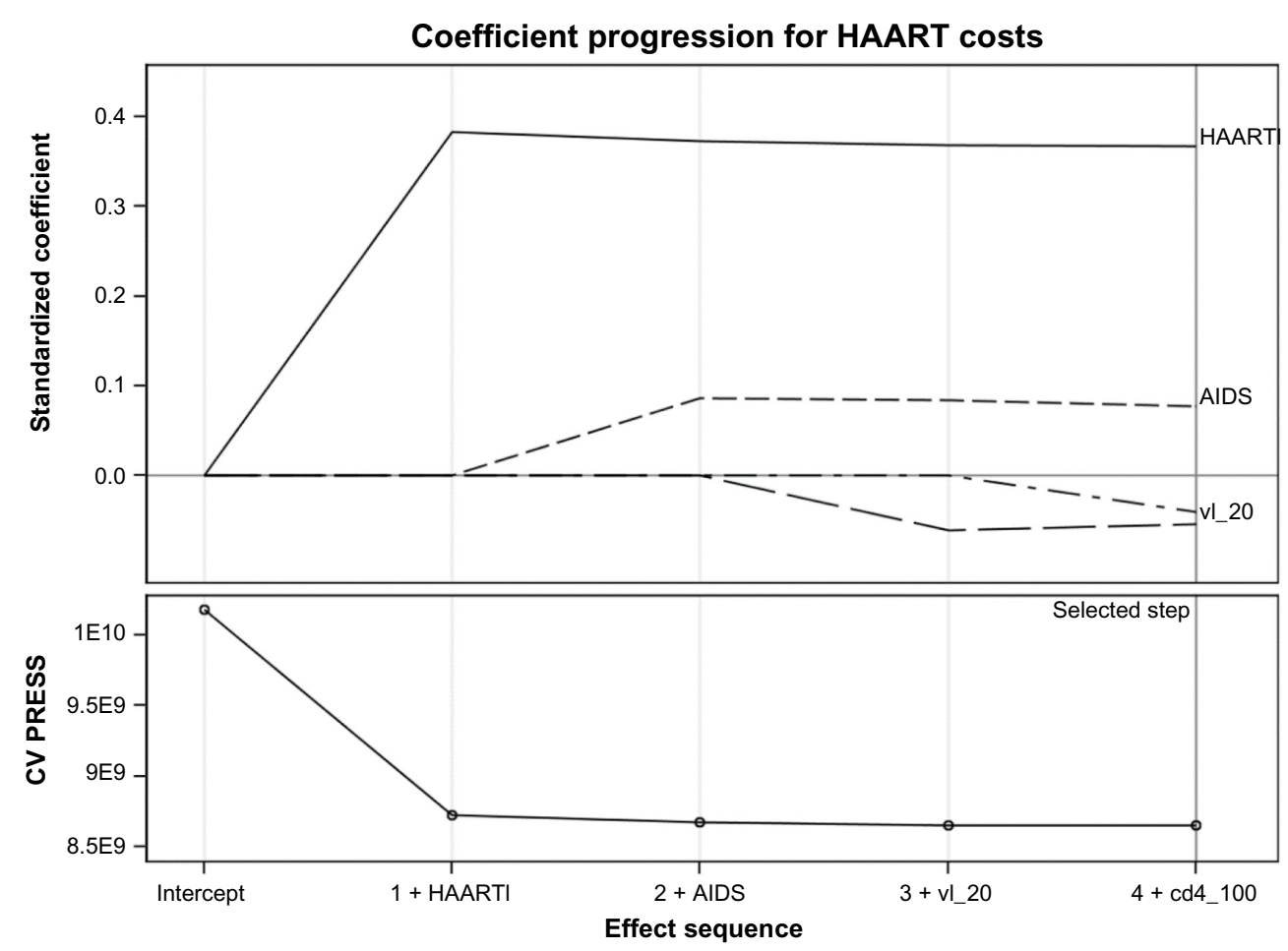

Figure I Coefficient progression for individual HAART costs, according to the GLMSELECT procedure. Factors were included in the analysis as follows: HAART line (haartl), AIDS event (AIDS), detectable HIV viral load (vl_20), and current CD4 count (cd4_100). Deflections from the starting point are directly correlated with the impact of each determinant on HAART costs, ie, the more the deflection is, the more HAART costs are influenced from such factor. HAART line is the most important factor influencing HAART costs.

Abbreviations: AIDS, acquired immune deficiency syndrome; HAART, highly active antiretroviral therapy; HIV, human immunodeficiency virus.

in the Lombardy region, finding a mean of $€ 8,471$ in 2009 and a constant trend to annual increase. .,20 $^{8}$

It is worth noting that each site faced with a specific population of patients, as shown in Table 1: site 3 took care of a higher percentage of previous intravenous drug users with a consequent higher percentage of $\mathrm{HCV}$-coinfected patients with a lower CD4 T-cell nadir; in contrast, site 4 had a higher percentage of sexually infected patients with a higher CD4 T-cell nadir. The variability in the assisted population may partly determine the observed differences in HAART costs; such differences, however, might also reflect different prescribing attitudes at different sites, ${ }^{21}$ in spite of excellent rates of virological suppression at all sites. Detailed analysis of the individual regimens, not included in this retrospective study, may help understanding of local differences.

Analysis of the larger patient population studied here shows that the most powerful determinant of HAART costs is the line of HAART. Similar results were shown in a recent evaluation of HIV costs in Germany, which reported on increased antiretroviral experience as related to higher expenses. ${ }^{22}$ Given that previous treatment failures compel physicians to resort to newer and more expensive drugs and regimens, such data are easy to interpret. However, the entity of this association was somewhat surprising, as it emerges by our additional statistical analyses and appears as one of the most relevant findings of the present study.

In the German evaluation of HIV costs, ${ }^{22}$ Mostardt et al reported that a low CD4 T-cell count at evaluation was a strong predictor of more intensive health care utilization in the following year, as also shown by other authors. ${ }^{21,23}$ Immune recovery at the time of cost calculation was indeed significantly related to HAART costs in our sample too, as patients with a good immunological response to HAART may be switched to less expensive regimens. Once more, future detailed analysis of the individual regimens (dual therapy, monotherapy, or others) may pinpoint specific preferences for simpler and less expensive strategies in such patients.

A detectable HIV viremia at the time of drug cost calculation was similarly associated with higher HAART costs. This is in contrast with a previous report from Rizzardini et $\mathrm{al}^{8}{ }^{8}$ indicating undetectable HIV viremia as associated with higher total and HAART costs for HIV care. The present finding, however, seems rather easy to explain, ie, virological failures are indeed more frequent in more advanced HAART lines and in patients with a longer duration of HIV infection, ${ }^{24}$ where many drugs have already been prescribed. However, 


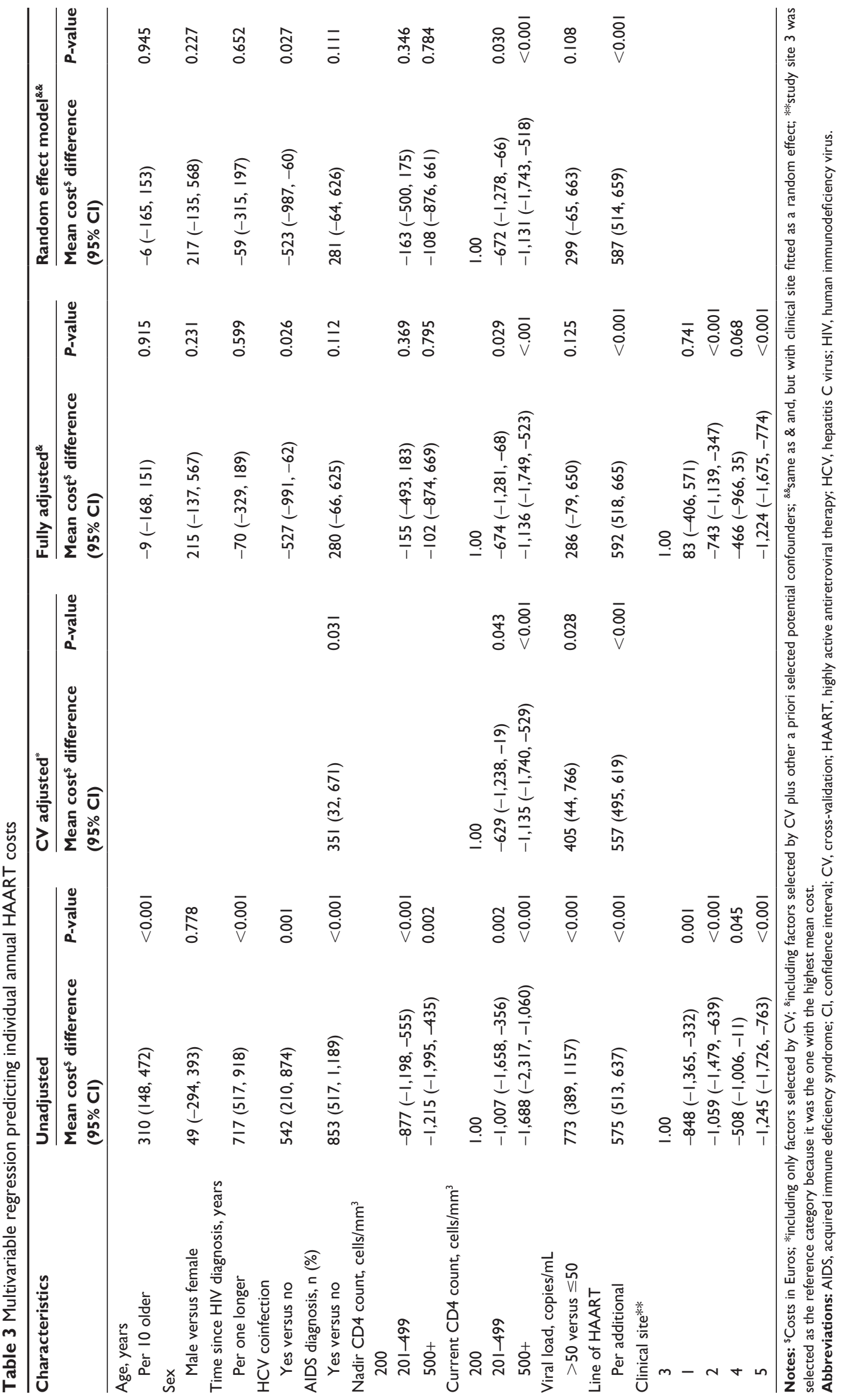


viral load $\geq 50$ copies $/ \mathrm{mL}$ was associated with higher costs independently of the line of HAART. This might be explained by the fact that persistence or relapse of low level HIV viremia and subsequent risk of virological failure ${ }^{25}$ make it difficult to simplify more complex and expensive rescue HAART regimens, independently contributing to the costly management regardless of number of HAART lines used. However, this association of HIV viremia with HAART costs did not remain significant in the final multivariable model.

HAART costs were higher in patients with a lower CD4 T-cell nadir. In our analyses, however, the correlation of costs with nadir CD4 T-cell count only showed a trend for significance in the multivariable models. Immune status at HIV diagnosis has been repeatedly associated with higher HIV care costs; in a different investigational model, Krentz et $\mathrm{al}^{7}$ showed that patients presenting with CD4 T-cell counts $<350$ cells $/ \mathrm{mm}^{3}$ had 2.5 times greater total costs than less advanced patients, with higher costs persisting as much as 5 years after presentation. The CD4 T-cell nadir was also evaluated by Rizzardini et al. ${ }^{8}$ In their multivariable analysis, patients with a CD4 T-cell nadir $<200$ cells $/ \mathrm{mm}^{3}$ had both higher total costs and HAART costs.

$\mathrm{HCV}$ coinfection has been identified as a determinant of higher total costs for HIV care, as well as for HAART and hospital admission costs. ${ }^{20}$ Even though there was also a direct association between HCV coinfection and higher HAART costs in univariable analyses in our study, all multivariable models surprisingly showed an inverse correlation, ie, HCV-positive patients have lower HAART costs. In fact, patients with $\mathrm{HCV}$ coinfection had more frequently advanced HAART lines, and lower nadir and current CD4 T-cell counts, and therefore this association remains surprising.

Our evaluation has some limitations. It is a cross-sectional analysis that is prone to reverse causality (difficult to establish whether using costly drugs had an impact on patients viroimmunological status or if, in contrast, are the level of the markers which are inducing different costs); moreover, the effect of dynamic changes in treatment usage and of surrogate markers of prognosis, fitted as time-dependent factors during the year of observation, could not be evaluated. Moreover, costs were calculated as an estimate from medical and pharmacy records, and may not reflect the exact expenses for the Italian health system.

\section{Conclusion}

Our study provides a novel insight into the strength of different independent determinants of HAART costs in a large representative sample of Italian HIV outpatients. Higher costs of HAART were strongly associated with previous treatment failures, and lower CD4 T-cell count at the time of evaluation. Further analyses to clarify the contribution of the single drug/ regimen to the annual costs of HAART are warranted.

\section{Acknowledgment}

We are very grateful to the Fondazione Onlus Camillo de Lellis per l'Innovazione e la Ricerca in Medicina, Pescara, Italy, which supported us throughout this study.

\section{Disclosure}

The authors report no conflicts of interest in this work.

\section{References}

1. Magoni M, Scarcella C, Vassallo F, et al. The evolving burden of HIV infection compared with other chronic diseases in northern Italy. HIV Med. 2011;12:129-137.

2. Levy AR, James D, Johnston KM, et al. The direct costs of HIV/AIDS care. Lancet Infect Dis. 2006;6:171-177.

3. Sullivan R, Peppercorn J, Sikora K, et al. Delivering affordable cancer care in high-income countries. Lancet Oncol. 2011;12:933-980.

4. Sloan CE, Champenois K, Choisy P, et al. Newer drugs and earlier treatment: impact on lifetime cost of care for HIV-infected adults. AIDS. 2012;26:45-56.

5. Krentz HB, Auld MC, Gill MJ; for the HIV Economic Study Group. The changing direct costs of medical care for patients with HIV/AIDS, 1995-2001. CMAJ. 2003;169:106-110.

6. Merito M, Bonaccorsi A, Pammolli F, et al. Economic evaluation of HIV treatments: the ICONA cohort study. Health Policy. 2005;74: 304-313.

7. Krentz HB, Gill J. Despite CD4 cell count rebound the higher initial costs of medical care for HIV-infected patients persist 5 years after presentation with CD4 cell counts less than 350 microL. AIDS. 2010;24: 2750-2753.

8. Rizzardini G, Restelli U, Bonfanti P, et al. The cost of HIV disease in Northern Italy: the payer's perspective. J Acquir Immune Defic Syndr. 2011;57:211-217.

9. Cohen MS, Chen YQ, McCauley M, et al; HPTN 052 Study Team. Prevention of HIV-1 infection with early antiretroviral therapy. $N$ Engl J Med. 2011;365:493-505.

10. Center for Disease Control and Prevention. Preexposure prophylaxis for the prevention of HIV infection on the United States 2014. Available from: http://www.cdc.gov/hiv/pdf/PrEPguidelines2014.pdf. Accessed June 8, 2014.

11. Foreman C, Gazzard B, Johnson M, Sharott P, Collins S. Maintaining cost-effective access to antiretroviral drug therapy through a collaborative approach to drug procurement, consensus treatment guidelines and regular audit: the experience of London HIV commissioners and providers. Sex Transm Infect. 2012;88:112-115.

12. Gazzard B, Moecklinghoff C, Hill A. New strategies for lowering the costs of antiretroviral treatment and care for people with HIV/AIDS in the United Kingdom. Clinicoecon Outcomes Res. 2012;4:193-200.

13. Helleberg M, Engsig FN, Kronborg G, et al. Retention in a public healthcare system with free access to treatment: a Danish nationwide HIV cohort study. AIDS. 2012;26:741-748.

14. Hall HI, Halverson J, Wilson DP, et al. Late diagnosis and entry to care after diagnosis of human immunodeficiency virus infection: a country comparison. PLoS One. 2013;8:e77763.

15. Parruti G, Vadini F, Sozio F, et al. Psychological factors, including alexithymia, in the prediction of cardiovascular risk in HIV infected patients: results of a cohort study. PLoS One. 2013;8:e54555. 
16. Cozzi-Lepri A, Prosperi MC, Kjær J, et al. Can linear regression modeling help clinicians in the interpretation of genotypic resistance data? An application to derive a lopinavir-score. PLOS ONE. 2011;6:e25665.

17. Tibshirani R. Regression shrinkage and selection via the Lasso. $J R$ Stat Soc Series B Stat Methodol. 1996;58:267-288.

18. Efron B, Hastie T, Johnstone I, Tibshirani R. Least angle regression. Ann Stat. 2004;32:407-499.

19. Tontodonati M, Sozio F, Vadini F, et al. A multifactorial risk score to evaluate baseline and antiretroviral-related toxicities relative to the costs of current antiretroviral regimens in a cohort of HIV-infected patients. Oral communication OC40 presented at the Ninth Italian Conference on AIDS and Retroviruses, June 10-12, 2012, Naples, Italy.

20. Rizzardini G, Restelli U, Bonfanti P, et al, Cost of human immunodeficiency virus infection in Italy, 2007-2009: effective and expensive, are the new drugs worthwhile? Clinicoecon Outcome Res. 2012;4: 245-252.

21. Oliva-Moreno J, López-Bastida J, Serrano-Aguilar P, Perestelo-Pérez L. Determinants of health care costs of HIV-positive patients in the Canary Island, Spain. Eur J Health Econ. 2010,11:405-412.
22. Mostardt S, Hanhoff N, Wasem J, et al. Cost of HIV and determinants of health care costs in HIV-positive patients in Germany: results of the DAGNA K3A Study. Eur J Health Econ. 2013;14:799-808.

23. Fong R, Cheng AC, Vujovic O, Hoy JF. Factors associated with virological failure in a cohort of combination antiretroviral therapy-treated patients managed at a tertiary referral centre. Sex Health. 2013;10: $442-447$.

24. Laprise C, de Pokomandy A, Baril JG, Dufresne S, Trottier H. Virologic failure following persistent low-level viremia in a cohort of HIV-positive patients: results from 12 years of observation. Clin Infect Dis. 2013;57: 1489-1496.

25. Krentz HB, Auld MC, Gill MJ. The high cost of medical care for patients who present late (CD4 $<200$ cells/microL) with HIV infection. HIV Med. 2004;5:93-98 


\section{Supplementary material}

The average squared error (ASE) evolved at each step until final step 4 was reached and inclusion of factors terminated because the ten error estimates computed by cross-validation (CV PRESS) stopped showing a decrease using the "onestandard-error" rule. The values for the adjusted R-square at the various steps were the following: $0.146,0.152,0.154$ and 0.155 at step 4 which was the optimal value criterion, indicated with a star symbol in the Figure S1 plot. The values for the standard R-square were similar (not shown). Step 4 was the chosen closing step for the chosen fit criteria of CV PRESS and for most of other fit criteria considered (eg, the adjusted R-square) or the previous step, removing current CD4 count (Akaike's Information Criterion [AIC], Bayesian
Information Criterion [BIC], see Figure S1). The ASE was greatly reduced when the line of highly active antiretroviral therapy (HAART) first entered the model. The plot of the improvements in ASE after the introduction of the various factors is key as it shows that the model including the line of therapy alone is a substantial improvement compared to the null model (with intercept only) but that adding any of the other factors determines only further small improvements to the predictive performance. These minor changes of the ASE were seen on the training, validation, and test datasets (data not shown). Results were similar when we used other methods of selection, such as least absolute shrinkage and selection operator (LASSO) or least angle regression (LAR).

\section{Fit criteria for HAART costs}
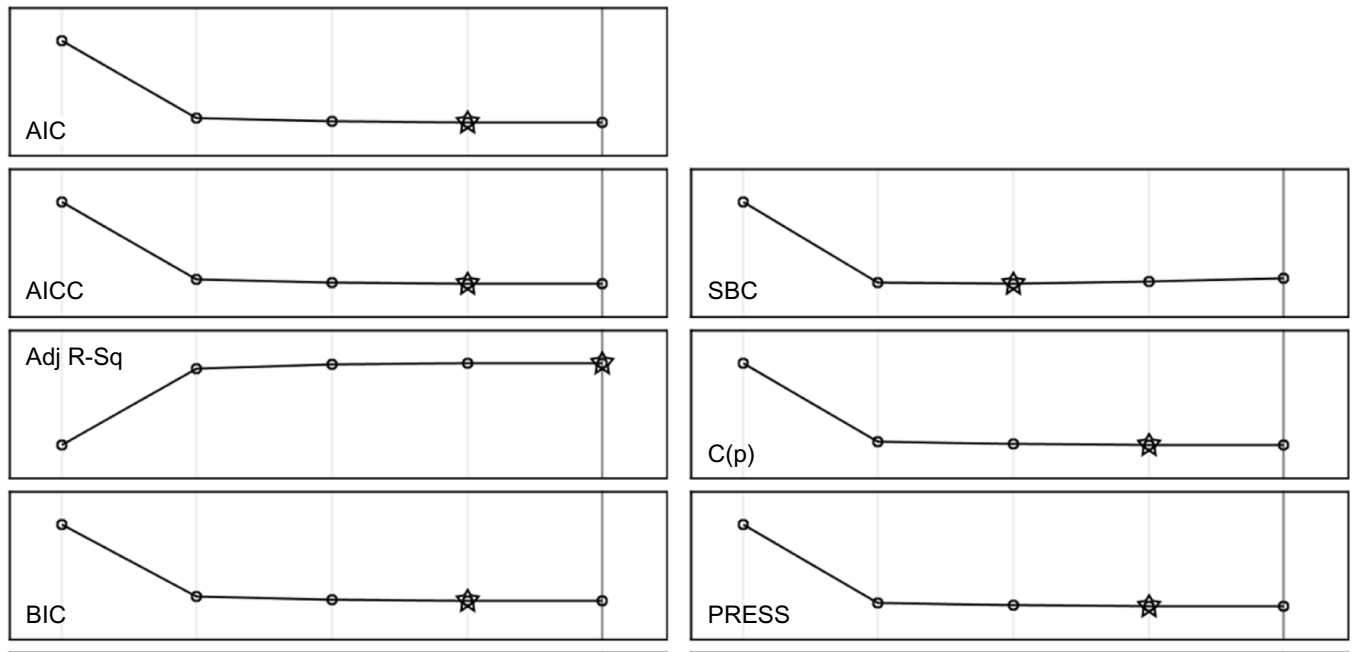

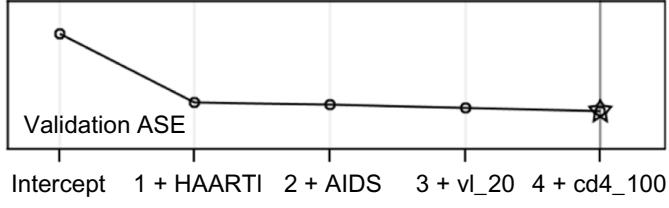

Effect sequence

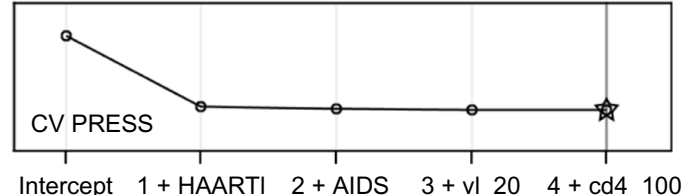

Effect sequence

W Best criterion value $\longrightarrow$ Step selected by CV PRESS

Figure SI Evolution of the ASE at each step of the GLMSELECT procedure. Factors were included in the analysis as follows: HAART line (HAARTI), AIDS event (AIDS), detectable HIV viral load (vl_20), and current CD4 count (cd4_100).

Abbreviations: Adj R-Sq, adjusted R-squared; ASE, average squared error; AIC, Akaike's Information Criterion; BIC, Bayesian Information Criterion; HAART, highly active antiretroviral therapy; LASSO, least absolute shrinkage and selection operator; LAR, least angle regression; AICC, corrected Akaike's information criterion; C(P), Mallows statistic; SBC, Schwarz Bayesian information criterion.

ClinicoEconomics and Outcomes Research

Dovepress

\section{Publish your work in this journal}

ClinicoEconomics \& Outcomes Research is an international, peerreviewed open-access journal focusing on Health Technology Assessment, Pharmacoeconomics and Outcomes Research in the areas of diagnosis, medical devices, and clinical, surgical and pharmacological intervention. The economic impact of health policy and health systems organization also constitute important areas of coverage. The manuscript management system is completely online and includes a very quick and fair peer-review system, which is all easy to use. Visit http://www.dovepress.com/testimonials.php to read real quotes from published authors.

Submit your manuscript here: http://www.dovepress.com/clinicoeconomics-and-outcomes-research-journal 